\title{
Teamwork: Crucible for Learning about Collaborative Leadership
}

\author{
By Lisa DeAngelis* \\ Sherry H. Penney ${ }^{\dagger}$ \\ Maureen A. Scully
}

\begin{abstract}
In teaching leadership development we have developed and revised a model of teamwork and collaboration, which has yielded innovative and positive results. Our study draws on insights from more than 90 project teams, gathered over twelve years of a mid-career executive education program designed specifically to teach collaborative leadership. The teams work on a strategic dilemma with a business association or community organization, highlighting the civic engagement aspect of collaborative leadership. Teams devise their own operating procedures, refine (not simply manage) the project, create working relationships with multiple stakeholders, and present a deliverable within the nine-month span of the program. The team experience emphasizes complexity and ongoing reflection. We identify seven concrete leadership skills that emerging leaders developed: coping with ambiguity, working cross-functionally beyond their usual expertise, knowing when to get outside help, understanding different stakeholders, working effectively across dimensions of diversity, dividing labor in a leaderless team, and handing off a project that advances but does not close a complex problem. Rather than implementing flawlessly on a project with defined metrics-which propels potential leaders partway up the ladder-participants shift toward the greater leadership challenges of defining scale and significance, changing course after listening carefully, and learning from obstacles. They emerge from the crucible of teamwork with leadership skills for everyday work and the future.
\end{abstract}

\section{Introduction}

The Center for Collaborative Leadership resides within the College of Management at the University of Massachusetts Boston. The premier product of the Center is the Emerging Leaders Program (ELP), a nine-month experiential leadership development program designed to teach rising leaders

\footnotetext{
*Director, University of Massachusetts Boston, USA.

${ }^{\dagger}$ Professor, University of Massachusetts Boston, USA.

${ }^{\star}$ Associate Dean, University of Massachusetts Boston, USA.
} 
the collaborative leadership model (Austin, 2000; Hackman, 2002) while increasing their understanding of the issues facing our region.

A major principle of the program is that teamwork would enhance individuals' skills in areas such as reflecting on one's own leadership style, learning to collaborate with varied stakeholders and outside sponsors, getting work done and dividing the labor on leaderless teams, and managing and completing a complex project on time. With our own continuous learning and adaptation of the team projects over time, we have fulfilled these expectations, based on reports from external stakeholders and systematic evaluations from team participants.

While many aspects of collaborative leadership can be taught and discussed, we found that teams and team projects provide a setting in which to practice and refine additional leadership behaviors. In linking leadership and teamwork, we are looking at teams as a crucible for learning a wide range of skills that have positive ramifications well beyond the team setting.

We open the paper with a description of our mid-career executive education program, which offers an appropriate setting for asking how collaborative leadership skills are learned, with broader implications for the organizations where these skills will be plied. We then describe several key collaborative leadership skills that are honed in the context of team projects, using specific illustrations. Throughout, we incorporate comments from participants, elicited as part of the self-reflection that we encourage as an element of learning to lead. We close with reflections on the importance of collaborative leadership - across levels of impact from teams to multiple stakeholders to societies - for the next generation of leaders and the pressing issues they will face.

\section{Executive Education Program for 'Emerging Leaders'}

Our program was born from the premise that, if organizations are to have effective leaders in the future, we must identify those potential leaders early and provide them with leadership education and skills. The leadership profile in the Greater Boston region at the turn of the century was in flux. Many prominent corporate executives were retiring or planning to retire. Some businesses that once were prominent in our area, and had traditionally provided business and civic leadership, no longer existed (e.g., AD Little, Wang Laboratories, Shawmut Bank, and Bay Bank). Others have been reconfigured by mergers and acquisitions. New organizations were emerging. Leadership in our region would be refreshed as individuals from these new entities were tapped in the future (S. H. Penney, Norasakkunkit, \& Leigh, 2002; S. Penney \& Neilson, 2010).

To address the concern about future leadership, the founding team of the Center for Collaborative Leadership met with senior executives in the business and non-profit communities to explore their concerns and ask what qualities they were seeking in future leaders. They confirmed the need to identify a 
succession pool immediately, specifically one with skills for working in teams and engaging collaboratively. They were also concerned that leadership reflect the growing diversity of the region, first seen in the 2000 census. Nonetheless, white males held most executive positions throughout the region with few females or people of color in those roles. This diversity continues to predominate in our region, as reflected in the 2010 census (see Figure 1).

Figure 1. Demographic Diversity in Boston

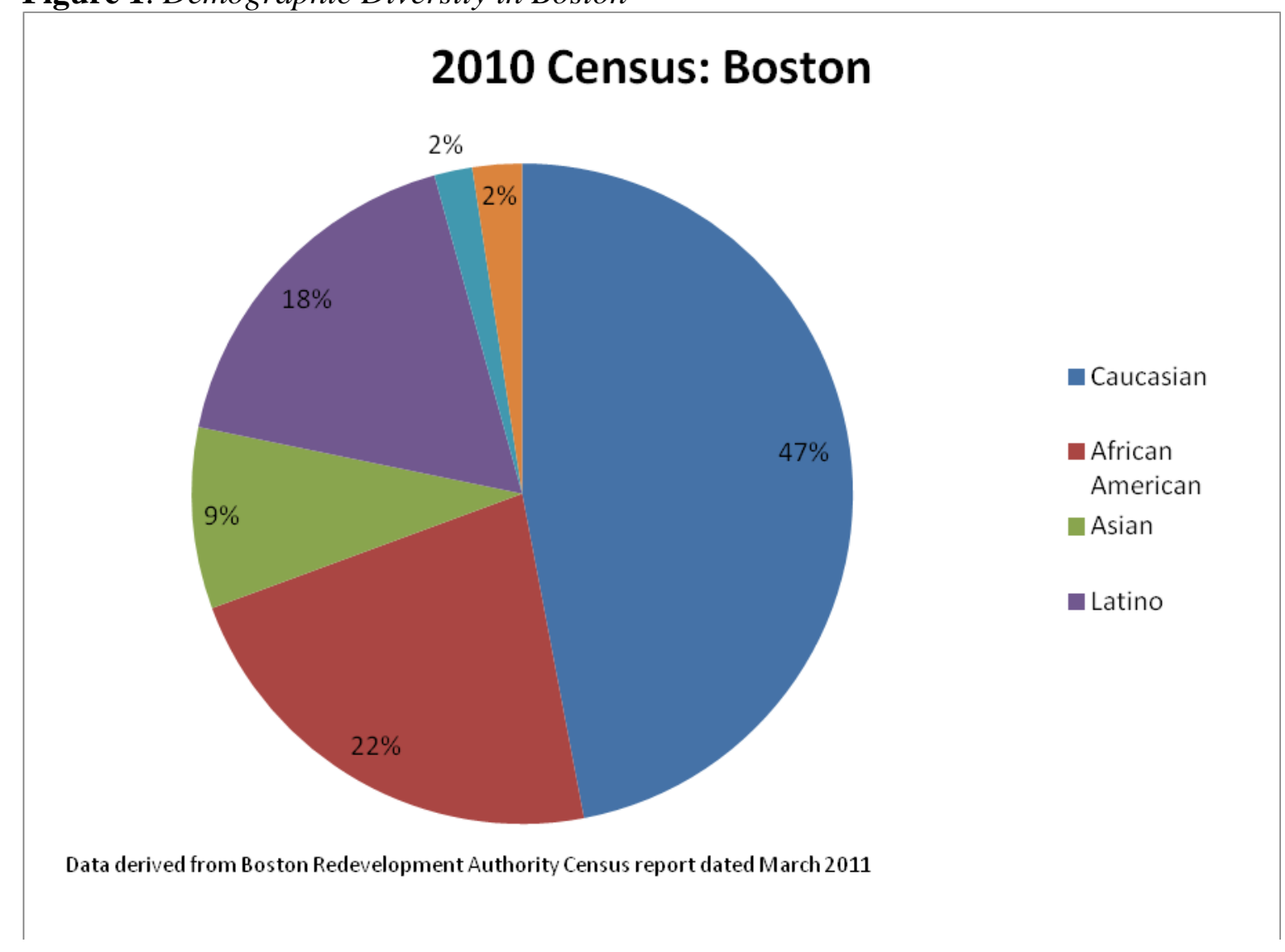

Our program's founders were business school professors, including a former CEO, with definite pedagogy ideas, stressing collaboration as the basic theoretical framework. We believed, from research and our own professional experience that better decisions occur when multiple points of view are heard. Breaking away from a leader centric model seemed warranted, even as scholars recognize that the 'Great Man' theory is tenacious (Hollander, 2009). Our program was also founded on the belief that leadership is not a trait from birth but a set of skills and habits of mind that can be learned through practice.

Our board agreed to the strategy of focusing on collaboration and teamwork, and they responded with several ideas, specifically about placing teams at the heart of the work. We had proposed focusing on various issues facing the region (housing, criminal justice, education, health care, etc.) at our monthly sessions. They recommended a revision of the curriculum to focus 
each monthly session on specific leadership skills. With their guidance, we designed each session around specific leadership skills/behaviors, and also we designed team projects on specific regional issues as a major approach to applying and reinforcing these leadership skills.

In 2002, we admitted our first cohort of rising professionals to an Emerging Leaders Program in the Center for Collaborative Leadership housed in a business school. For the last twelve years we have been privileged to work intensely with groups of emerging leaders. To date, 523 have completed the program and another 44 are currently enrolled for another session in September 2014. Their overall average age is 37 , and the majority of them already have graduate degrees (MBA's, MA's, MD's, and JD's). For the 2002-2014 timeframe, we have had 38 percent individuals of color and 57 percent females, so the diversity of the group bodes well for the region. Some 52 percent have come from the corporate sector with the non-profit sector numbering 32 percent and the governmental sector at sixteen percent. They represent the major businesses and non-profit organizations in our region.

Each fellow, as we call them, has a sponsor or nominator in their home organization who supports their participation. Some organizations that have partnered with us for multiple years now have their own alumni cohort of ten or more former fellows, who network to provide leadership within their organization.

Our focus is regional, but our composition of midcareer professionals representing corporate, non-profit, and government sectors would also be found in other large urban areas in the United States. While taking a regional focus, our programming recognizes that the fellows come from varied local and global backgrounds and that the new business and societal challenges are all globally embedded.

\section{Team Composition}

Each cohort of approximately forty fellows is divided into teams at the beginning of the program. The team size is typically five members (35\% of all teams) or six members $(46 \%)$.

Learning across diversity is a key element of learning to lead and of seeding future civic leadership for the region. Therefore, we have created teams that are diverse in sector (see Figure 2), racial and ethnic background (see Figure 3), and gender (see Figure 4). Moreover, we track the fellows' experiences when those from historically under-represented groups occupy a token role ( 1 member) or hold a more significant voice ( 3 or more members). We ask the fellows to join us in being mindful of team composition, through a team formation process that is itself participative. These guiding principles for team formation and operation have emerged from our own experiences in offering the program. During the team experience, cross-sector networking is encouraged and arises organically given the team composition. Initial misunderstandings, as participants come with different backgrounds and 
assumptions, become a basis for learning.

Figure 2. Distribution within Teams of Corporate, Non-profit, and Government Members over the Twelve Years of the Program

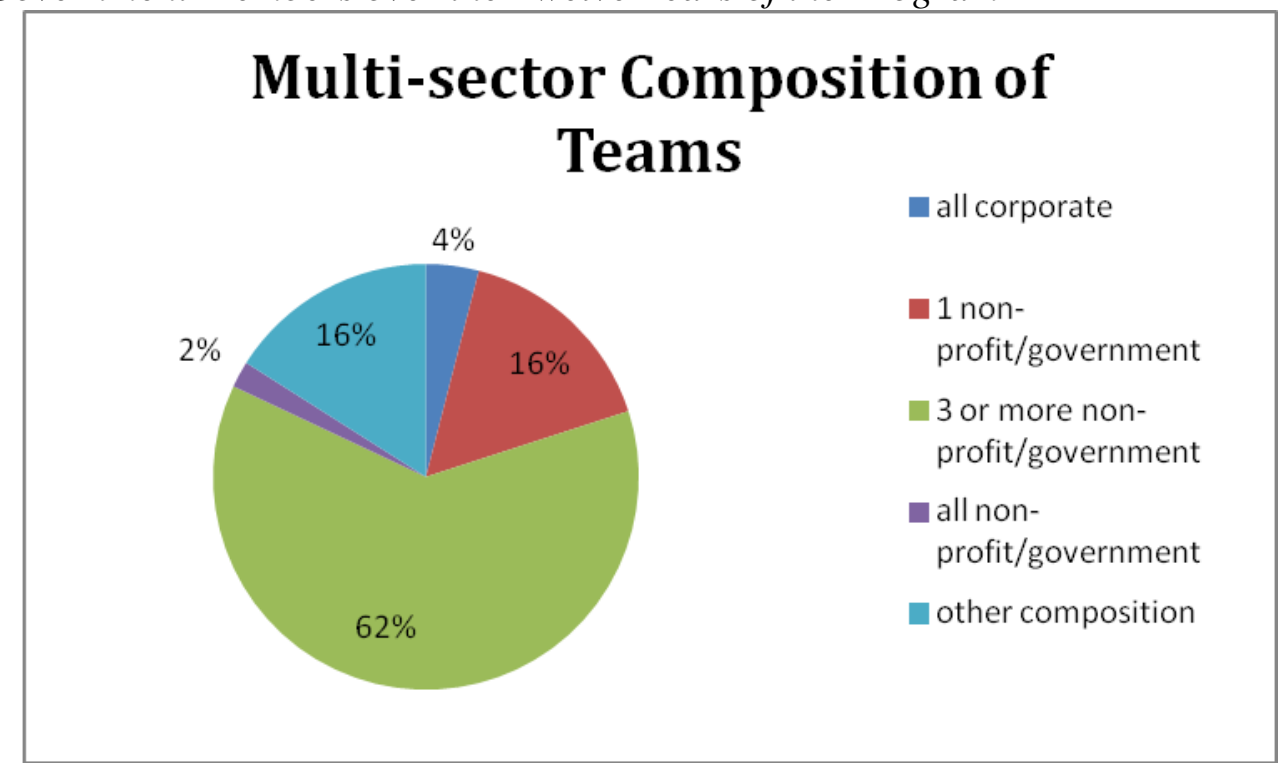

Figure 3. Distribution within Teams of People of Color and White People over the Twelve Years of the Program

\section{Composition of diverse teams}

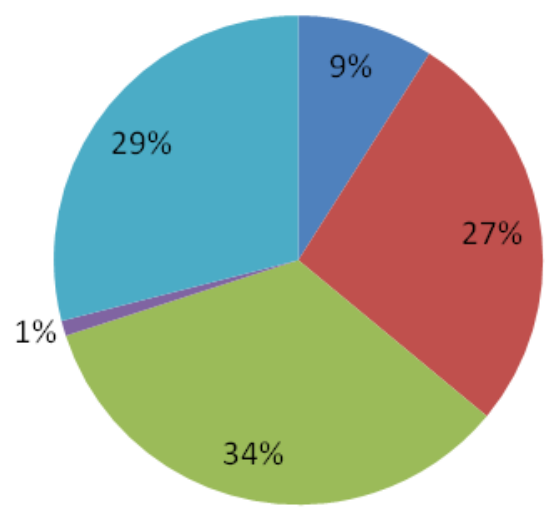

0 people of color

1 person of color

3 people of color

all people of color

other composition 
Figure 4. Distribution within Teams of Female and Male Members over the Twelve Years of the Program

\section{Female representation on teams}

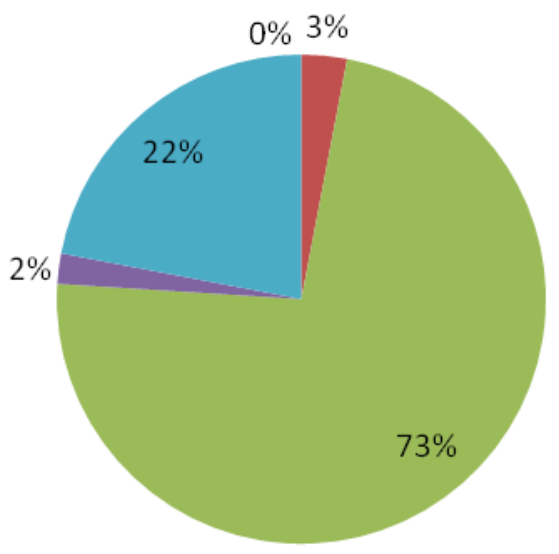

n 0 females

1 female

a 3 or more females

all female

nother composition

\section{Team Projects: Focus on Civic Issues}

The team experience distinguishes our program from many other leadership development programs. Program staff work with regional leaders to define meaningful and well-scoped projects that focus on civic and economic issues facing the region. As emerging leaders rise in their careers, they take on a leadership mantle not only in their own organizations, but more broadly in their profession, their industry, and their region.

Team projects have addressed a range of pressing economic and societal issues, such as:

- Easing the school to work transition, especially for at-risk youth

- Retaining young professionals in the Boston area (prompted by Census data that there was a net outflow)

- Ensuring affordable housing, which supports workers whose contributions are vital (retail clerks, child care providers, librarians, etc.)

- Giving Boston a strong, global social media presence to attract investors, entrepreneurs, workers, etc.

- Clarifying the business case for corporate social responsibility

- Supporting neighborhoods to become racially integrated and welcoming

We discovered over time that lessons about the wider environment in which businesses operate and about the importance of civic engagement become vivid without our actively flagging them as such. The projects were 
initially conceived as a vehicle to engage emerging leaders in a team setting with timely deliverables that simulate a real work setting (Houde, 2007). But they yielded insights about how to provide leadership beyond organizational boundaries that affects the economic viability of a region. We have consistently seen that fellows increase their commitment to and involvement in a variety of civic issues. Some 40 percent have joined prominent non-profit boards of directors and others have volunteered in their communities (CommunityBuild, 2010).

\section{Developing Leadership Skills: Team Projects}

These broad benefits of collaborative leadership are significant. But we also noticed benefits that were very concrete and applied. Very practical leadership skills are learned - often exactly the ones that will propel rising leaders from superb implementers of strategies to leaders who craft strategies in the face of complexity.

Project sponsors as well as executives in the organizations the fellows come from comment favorably on the skills fellows bring back to their home organization. At our 2010 presentation of team projects (see www.leaders. umb.edu for more information), Fred Ramos, Senior Managing Director of State Street Corporation, an early supporter of the program, spoke of how he has watched several emerging leaders from his division over the years develop a new professional confidence and awareness of the broader environment of business.

We have identified several leadership lessons that the fellows have garnered through the program and practiced in the team projects (DeAngelis, Penney, \& Scully, 2014). As the team project is meant to mirror experiences like those of top executives, an early task of the team is to define the scope of the project. Each project sponsor offers an initial perspective on the work they are seeking (e.g., 'we need to create a communication strategy to effectively reach our varied audiences.'). Through the process of distilling this into a meaningful, manageable project scope, the team learns how to manage ambiguity. Once this is completed, the team then needs to set about how they will endeavor to deliver this project. During this phase of the work, the teams develop skills in being able to work on projects outside of one's expertise, work across dimensions of diversity, and divide labor in a leaderless team.

As the project gets underway, inevitably, the teams hit roadblocks (whether these be internal to the team or with outside stakeholders). Some teams learn the valuable lesson of knowing when to get outside help earlier than others. The project also teaches the importance of managing multiple stakeholders as the fellows work to meet the expectations of their project sponsor, their project team mates, the ELP, and their manager or nominator back in their home organization.

Finally, as the program comes to a close, the project team is faced with 
turning the work back to the client. The project team manages multiple aspects of how to hand off a complex and unclosed project, including some mix of finished reports, data yet to be analyzed, website designs or other proposals, and tacit knowledge acquired along the way. The nature of our projects is that the team might make substantial headway, but leave in place a new set of issues that the project sponsor or a future team of fellows might continue. Stewarding projects that do not have neat boundaries is a skill of top leaders.

\section{Fellows' Learning From Reflection On Leadership Styles}

In the preceding section, we described the projects, using illustrations of lessons that we believe have come to life for the participants. We test this belief by regularly soliciting feedback from participants. This feedback process encourages fellows to adopt the practice of pausing for self-reflection, another essential element in their future as collaborative leaders. It also guides our ongoing program improvements. We use several measurements to assess how participants experience their own growth as leaders, including general measures of leadership skills and questions specific to the team projects. In this section, we will report on a quantitative measure of leadership skills and share some reflective comments from participants.

Each year the fellows are asked to take the Leadership Practices Inventory (LPI) (Posner \& Kouzes, 1988) prior to beginning the program and again at the end of the program (see Figure 5). This 30-item assessment allows the fellows to assess their capabilities and see how they change over time. While the data show that the fellows' self-assessment ratings improved in virtually every item, the three with the most significant improvement were related to a leadership stance based on seeing the big picture and being inclusive- - essential elements of collaborative leadership:

1) 'I am clear about my philosophy of leadership' (difference = 1.21)

2) 'I show others how their long-term interests can be realized by enlisting a common vision' (difference $=1.17$ )

3) 'I publicly recognize people who exemplify commitment to shared values' $($ difference $=1.08)$ 
Figure 5. Aggregated Leadership Practices Inventory Data over the Twelve Years of the Program

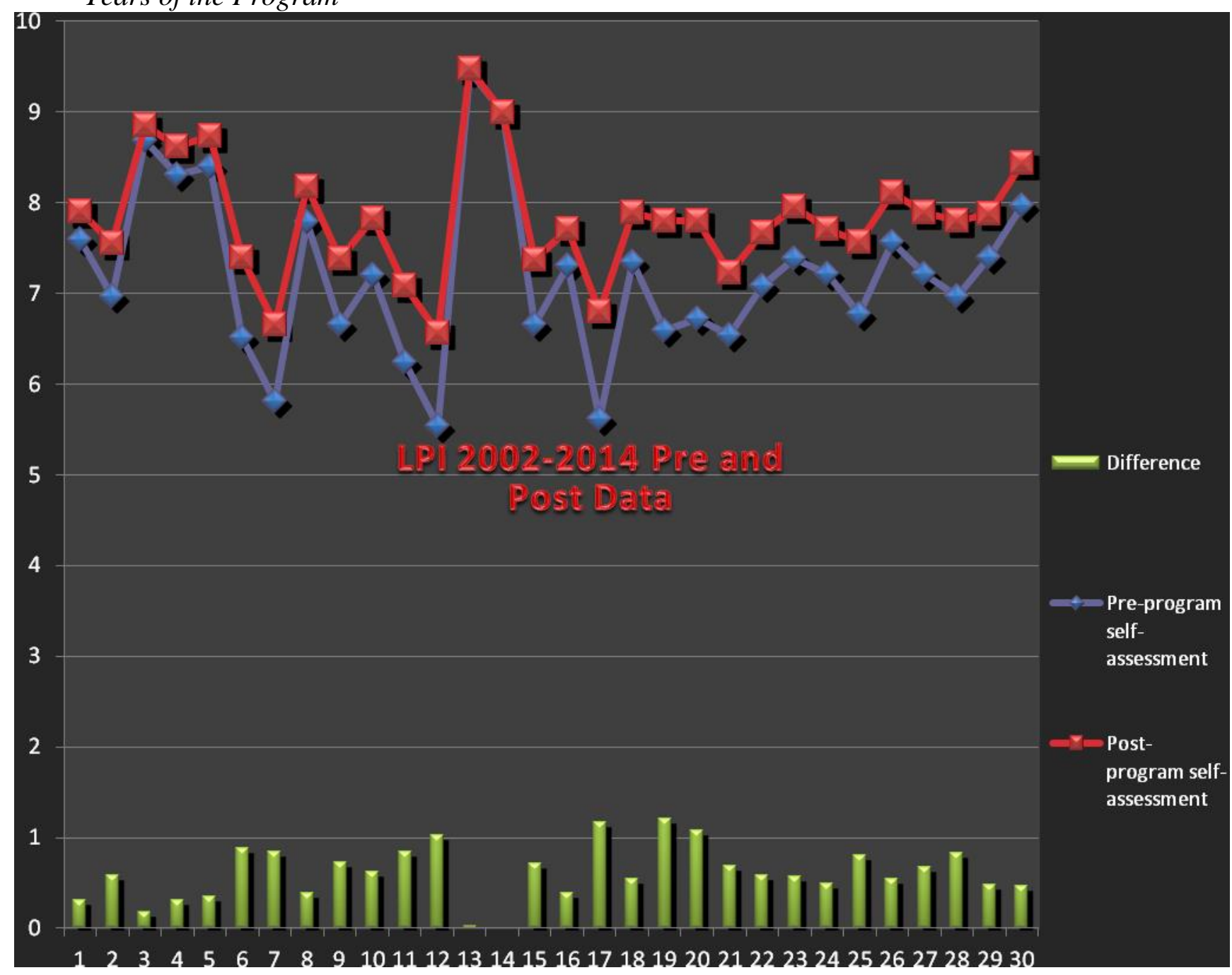

In addition to the LPI, we assess realization of our program goals through surveys administered at regular intervals throughout the program. One question at the end of the program specifically asks, 'What do you feel the benefits of the team project activity have been for you?' Here is a sample of responses from the fellows, about team project dynamics and impacts.

'The team project allowed me to meet and work with people I would have otherwise never socialized and associated with. The project also helped me to better understand the business world and how it works. The project also taught me persistence and determination - the lack of clarity served to bring us closer together. Our frustration lent itself to problem-solving.' Naima Abdal-Khallaq, English Teacher, Charlestown High School

'It brought people of different backgrounds and experiences to lend their expertise and leverage some of their connections to try and effect some change 
[regarding problems that] had been institutionalized for a long time.' Paul Francisco, Vice President of Global Inclusion, State Street Corporation

As the program has matured, we have learned to be explicit about linking the skills that they are learning in the classroom to the work of the project, we encourage the fellows to practice the skills that they are learning in this program. This enables them to begin becoming comfortable with the skill without the inherent risk associated with experimenting in their workplace. Additionally, participants have the opportunity to try out new roles, roles they may not play in their everyday work, in a safe environment - to be a project manager, external presenter, or conflict resolver. Beyond the embodiment of these explicit leadership skills comes the tacit knowledge that has been evidenced above.

In addition to the data outlined above we also have many examples of former fellows achieving significant leadership roles within their organizations. One fellow is a CEO of a multinational corporation. Another was medical director for the division of public health for the Commonwealth; another-also an MD - is chair of a major department at Lahey Clinic. The recent chair of our alumni association heads a major foundation; one has become CEO of the family business. Others have assumed major roles in state and local government; one has been appointed to a major hospital board of directors. Still others have become entrepreneurs. One founded a high tech company, specializing in web work, and another founded a public relations firm focusing on social media.

We could cite more but the overall result is that our alumni are stepping into leadership roles both regionally and globally. Moreover, as they assume more significant roles in their own careers, they have also increased their civic commitment in a variety of ways. They are putting their leadership development work into practice and are helping to change the leadership profile and economic vibrancy of our region.

\section{Conclusion}

Through our work with more than 90 project teams, we have demonstrated that there is a strong connection between teamwork and learning about collaborative leadership. Emerging leaders develop the types of collaborative leadership skills that they will likely require in order to address future issues in their organizations, their sectors or industries, their region, and even to address global challenges that manifest in urban areas (Sampson, 2012). Emerging leaders will be called upon to rise to these challenges. They will need to understand diversity, both to collaborate with diverse partners and to ensure that organizational and societal goals of diversity and inclusion are fulfilled. We have found that learning to lead while guided by a broader vision is not just a matter of grappling with big ideas and grand visions. Rather, team projects and their very concrete and practical challenges become a crucible for learning about leadership. 
The lessons from the project teams describe an additional set of leadership skills forged in the setting of teamwork. Emerging leaders evolve in their sense of who they are as a leader, realizing the power of being a collaborative leader who shares resources, networks, and perspectives to achieve common goals.

\section{References}

Austin, J. E. 2000. The collaboration challenge: how nonprofits and businesses succeed through strategic alliances (1st ed.). San Francisco, Calif: JosseyBass Publishers.

CommunityBuild. 2010. UMass Boston Center for Collaborative Leadership Emerging Leaders Program Survey Executive Summary Report.

DeAngelis, L., Penney, S., and Scully, M. 2014. Leadership Lessons from Teamwork. Leader to Leader, 2014 (73), 19-25. doi:10.1002/lt1.20135

Hackman, J. R. 2002. Leading teams: setting the stage for great performances. Boston, Mass: Harvard Business School Press.

Hollander, E. P. 2009. Inclusive Leadership: The Essential Leader-follower Relationship. Taylor \& Francis.

Houde, J. 2007. Analogically Situated Experiences: Creating Insight Through Novel Contexts. Academy of Management Learning \& Education, 6(3), 321-331. doi:10.5465/AMLE.2007.26361623

Penney, S. H., Norasakkunkit, V., and Leigh, J. 2002. New Leaders for the new century. In C. Cherrey and L. R. Matusak (Eds.), Building Leadership Bridges 2002 (pp. 48-58). International Leadership Association.

Penney, S., and Neilson, P. 2010. Next Generation Leadership: Insights from Emerging Leaders (1st ed.). Palgrave Macmillan.

Posner, B. Z., and Kouzes, J. M. 1988. Development and validation of the Leadership Practices Inventory. Educational and Psychological Measurement, 48(2), 483-496. doi:10.1177/0013164488482024

Sampson, R. J. 2012. Great American City: Chicago and the Enduring Neighborhood Effect. University of Chicago Press. 
